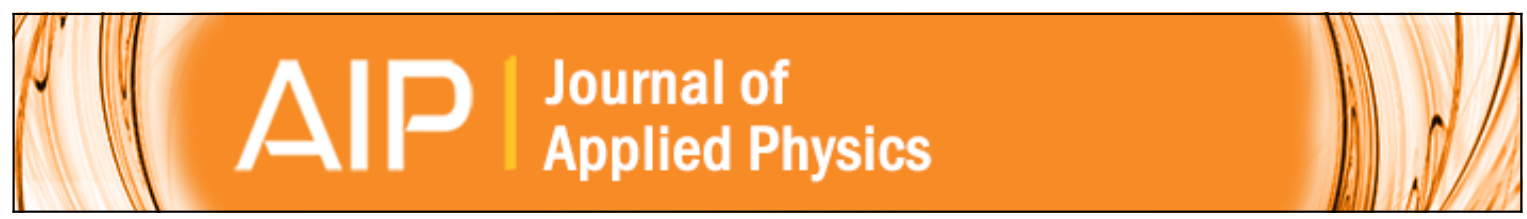

\title{
Magnetic force microscopy of single crystal magnetite (Fe304)(abstract)
}

R. Proksch, S. Foss, C. Orme, S. Sahu, and B. Moskowitz

Citation: Journal of Applied Physics 75, 6892 (1994); doi: 10.1063/1.356771

View online: http://dx.doi.org/10.1063/1.356771

View Table of Contents: http://scitation.aip.org/content/aip/journal/jap/75/10?ver=pdfcov

Published by the AIP Publishing

\section{Articles you may be interested in}

Metallization of magnetite ( $\mathrm{Fe} 3 \mathrm{O} 4$ ) under high pressure

J. Appl. Phys. 89, 7347 (2001); 10.1063/1.1359460

Fabrication and properties of heteroepitaxial magnetite ( $\mathrm{Fe} 3 \mathrm{O} 4$ ) tunnel junctions

Appl. Phys. Lett. 73, 3282 (1998); 10.1063/1.122745

Magnetic anomalies in single crystal Fe3O4 thin films

J. Appl. Phys. 75, 6097 (1994); 10.1063/1.355472

57Fe Hyperfine Fields in Magnetite (Fe3O4)

J. Appl. Phys. 40, 1411 (1969); 10.1063/1.1657696

Some Magnetic Properties of Magnetite (Fe3O4) Microcrystals

J. Appl. Phys. 39, 5703 (1968); 10.1063/1.1656035

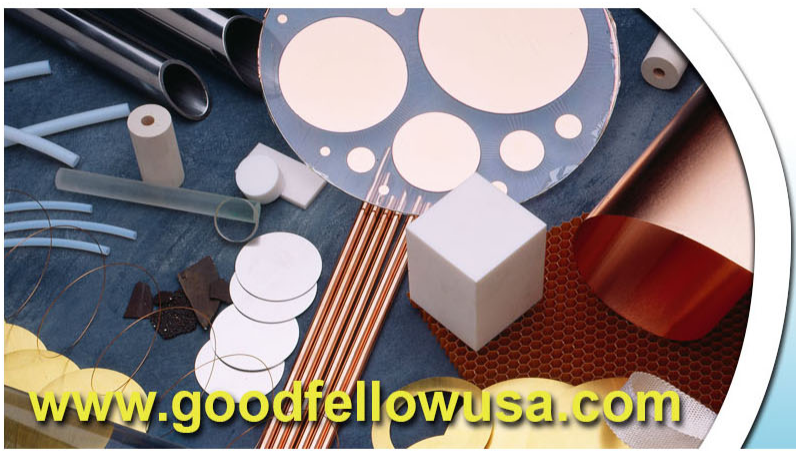

BODIFE|III

metals • ceramics $\cdot$ polymers composites $\bullet$ compounds • glasses

Save $5 \%$ • Buy online 70,000 products $\cdot$ Fast shipping 


\section{Magnetic force microscopy of single crystal magnetite $\left(\mathrm{Fe}_{3} \mathrm{O}_{4}\right)$ (abstract)}

R. Proksch ${ }^{\text {a) }}$ and S. Foss ${ }^{\text {a) }}$

School of Physics and Astronomy, University of Minnesota, Minneapolis, Minnesota 55455

C. Orme

Department of Physics, University of Michigan, Ann Arbor, Michigan

S. Sahu and B. Moskowitz

Institute for Rock Magnetism, University of Minnesota, Minneapolis, Minnesota 55455

The micromagnetic domain structure of a magnetite $\left(\mathrm{Fe}_{3} \mathrm{O}_{4}\right)$ single crystal has been studied using a magnetic force microscope (MFM). The MFM responds to the perpendicular component of the stray ficld above the magnetite surface. The sample was polished in the (011) plane. In this case, there are two easy magnetic axes parallel to the surface. Surface domains observed near cracks and edges have a complex closure structure (see Fig. 1), while walls seen far from such boundaries have a sinusoidal structure. Of particular interest is the presence of walls with either even or odd symmetry of the perpendicular stray field component across the transition. These can be conventionally modeled as Bloch or Neel walls, respectively. Both types of walls have been modeled and compared with the experimentally observed structures. We find the Bloch domain walls to be about $300 \mathrm{~nm}$ wide, nearly twice the value expected from bulk wall calculations. This distinction is consistent with a surface broadening of the domain wall due to magnetostatic effects. ${ }^{1}$

\footnotetext{
2)Work sponsored by ONR Grant No. N00014-89-J-1355.
}

${ }^{1}$ M. R. Scheinfein, J. Unguris, R. J. Celotta, and D. T. Pierce, Phys. Rev. Lett. 63, 668 (1989).

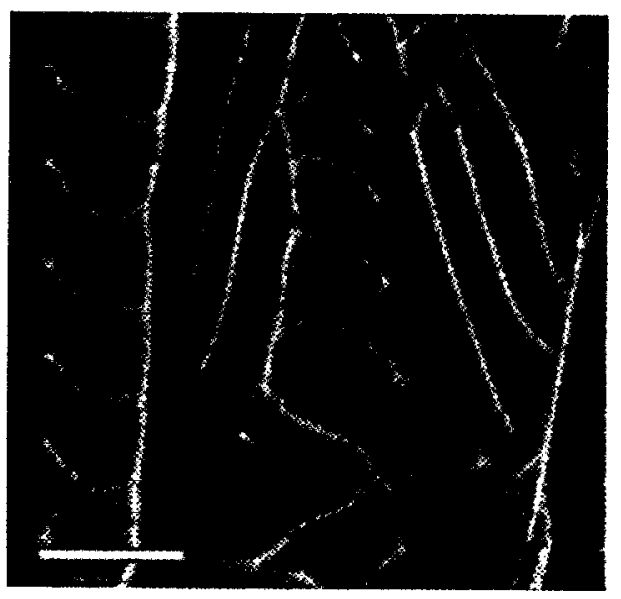

FIG. 1. MFM image of domain walls in a single crystal of magnetite. Bloch walls around closure structures are clearly visible. The domain walls are an average of $300 \mathrm{~nm}$ wide. The white scale bar in the lower left is $12 \mu \mathrm{m}$. 